\title{
Chromosome 9p Deletion Syndrome and Sex Reversal: Novel Findings and Redefinition of the Critically Deleted Regions
}

\author{
Roberta Onesimo, ${ }^{1}$ Daniela Orteschi, ${ }^{2}$ Maria Scalzone, ${ }^{1}$ Aurora Rossodivita, ${ }^{1}$ Lorenzo Nanni, ${ }^{1}$ \\ Gian Franco Zannoni, ${ }^{3}$ Giacinto Marrocco, ${ }^{4}$ Domenica Battaglia, ${ }^{1}$ Carlo Fundarò, ${ }^{1}$ and Giovanni Neri ${ }^{2 *}$ \\ ${ }^{1}$ Department of Pediatrics, Catholic University School of Medicine, Rome, Italy \\ ${ }^{2}$ Institute of Medical Genetics, Catholic University School of Medicine, Rome, Italy \\ ${ }^{3}$ Institute of Pathology, Catholic University School of Medicine, Rome, Italy \\ ${ }^{4}$ Department Pediatric Surgery, San Camillo De Lellis Hospital, Rome, Italy
}

Manuscript Received: 20 February 2012; Manuscript Accepted: 21 April 2012

Deletions of the short arm of chromosome 9 are associated with two distinct clinical entities. Small telomeric 9p24.3 deletions cause genital anomalies in male subjects, ranging from disorder of gonadal sex to genital differentiation anomalies, while large terminal or interstitial deletions result in 9p-malformation syndrome phenotype. The critical region for non-syndromic 46 , XY sex reversal was assigned to a $1 \mathrm{Mb}$ interval of chromosome $9 \mathrm{p}$, extending from the telomere to the $D M R T$ genes cluster. The 9p-syndrome was assigned to bands 9p22.3p24.1, but a phenotypic map has not been established for this condition, probably because of the lack of detailed molecular and/or phenotypic characterization, as well as frequent involvement of additional chromosome rearrangements. Here, we describe a unique patient with a small isolated $9 \mathrm{p}$ terminal deletion, characterized by array-CGH and FISH, who shows a complex phenotype with multiple physical anomalies, resembling the $9 \mathrm{p}-$ syndrome, disorder of sex development with gonadoblastoma, congenital heart defect and epilepsy. The observed deletion includes the 46,XY sex-reversal critical region, excluding the region so far associated with the 9p-syndrome. Genotypephenotype correlations are tentatively established comparing our patient to seven other previously reported males with isolated terminal 9p deletions, finely defined at a molecular level. Our observations expand the $9 \mathrm{p}$ deletion clinical spectrum, and add significantly to the definition of a 9p-syndrome critical region. (c) 2012 Wiley Periodicals, Inc.

Key words: chromosome 9p deletion; 9p deletion syndrome; trigonocephaly; congenital heart defect; gonadal dysgenesis; gonadoblastoma; ambiguous genitalia; XY sex reversal; epilepsy

\section{INTRODUCTION}

Since the first report by Alfi et al. [1973] over 180 cases of 9p deletion (9p-) syndrome have been described. This syndrome represents a clinically variable and genetically heterogeneous condition, with a

\section{How to Cite this Article:}

Onesimo R, Orteschi D, Scalzone M,

Rossodivita A, Nanni L, Zannoni GF, Marrocco G, Battaglia D, Fundarò C, Neri, G. 2012. Chromosome 9p deletion syndrome and sex reversal: Novel findings and redefinition of the critically deleted regions. Am J Med Genet Part A 158A:2266-2271.

wide spectrum of phenotypic manifestations and variable size of causal deletions.

The main clinical findings are intellectual disability, congenital hypotonia and a range of cranio-facial abnormalities, such as trigonocephaly, prominent forehead, flat occiput, epicanthic folds, small palpebral fissures, arching eyebrows, hypertelorism, midface hypoplasia with short nose, depressed nasal bridge, anteverted nostrils, thin upper lip vermilion, long philtrum, microstomia, micrognathia, malpositioned and missing teeth, short neck with a low posterior hairline, low-set, malformed, and posteriorly angulated ears [Young et al., 1982; Huret et al., 1988; Hou, 2003]. Although less frequently, other anomalies, involving multiple organs, have been observed in patients with $9 \mathrm{p}$ deletions [Shashi et al., 1998; Muroya et al., 2000; Hauge et al., 2008], that is, cardiac defects, epilepsy, inguinal hernia, omphalocele, choanal atresia, scoliosis, non-ketotic hypoglycemia.

Roberta Onesimo and Daniela Orteschi contributed equally to this work. ${ }^{\star}$ Correspondence to:

Giovanni Neri, MD, Istituto di Genetica Medica, Università Cattolica del S. Cuore, Largo F. Vito, 100168 Roma, Italy. E-mail: gneri@rm.unicatt.it Article first published online in Wiley Online Library

(wileyonlinelibrary.com): 20 July 2012

DOI 10.1002/ajmg.a.35489 
Deletions of the terminal portion of $9 p$ are associated in males with genital anomalies which can vary significantly from disorders of gonadal sex (i.e., gonadal dysgenesis or the presence of an ovotestis) to disorders of genital differentiation (i.e., cryptorchidism and/or hypospadias) [Muroya et al., 2000; Ogata et al., 2001; Fujimoto et al., 2004].

The deletion breakpoints cluster in bands 9p22-p24 and in most patients additional rearrangements have been identified involving other chromosomes. No clear-cut genotype-phenotype correlations have been established.

In general, telomeric deletions cause gonadal dysgenesis, while more proximal, interstitial deletions result in the malformation syndrome outlined above. The respective consensus regions (CRs) are reportedly located at 9p24.3, extending from the DMRT genes (included) to the telomere, and at 9p22.3-p24.1 [Flejter et al., 1998; Guioli et al., 1998; Christ et al., 1999; Raymond et al., 1999; Calvari et al., 2000; Kawara et al., 2006; Faas et al., 2007; Swinkels et al., 2008].

Except for a single case of sex reversal that was associated to a telomeric deletion not including the DMRT genes, in all previously described cases the deletion included the three DMRT genes (DMRT1,DMRT3, and DMRT2) [Calvari et al., 2000].

We describe a unique patient where a small terminal 9p deletion is associated with a complex phenotype, consisting of multiple physical anomalies, resembling the 9p-malformation syndrome, disorder of sex development with gonadoblastoma, congenital heart defect, and epilepsy.

\section{CLINICAL REPORT AND GENETIC TESTS}

The patient was the fourth child of non-consanguineous parents of Caucasian ethnicity. The older siblings are healthy. Pregnancy and delivery were reportedly uneventful. The child was born at 41 weeks gestation by spontaneous vaginal delivery. Birth weight was $4,500 \mathrm{~g}$ $(+2.4 \mathrm{Z}$-score SD), length $56 \mathrm{~cm}(+2.4 \mathrm{Z}$-score SD), cranial circumference $38 \mathrm{~cm}(+2.4 \mathrm{Z}$-score SD), and Apgar scores were 9 and
10 at 1 and $5 \mathrm{~min}$, respectively. At birth a female sex was assigned, based on the aspect of external genitalia.

In the second day of life a cardiac murmur was detected. ECG and cardiac ultrasound showed patent ductus arteriosus, bicuspid aortic valve, and severe hypoplasia of the aortic arch, which required surgical correction.

At 1 month of age the family pediatrician recognized genital ambiguity, as well as craniofacial anomalies, leading to genetic and hormonal investigations. Chromosomes were apparently normal male (46,XY) and FISH analysis confirmed the presence of the SRY gene. Androgen insensitivity and 5alpha-reductase deficiency were ruled out by hormonal tests (basal serum testosterone $2.33 \mathrm{ng} / \mathrm{ml}$ and DHEAS $0.48 \mathrm{ng} / \mathrm{ml}$ ).

At the age of 3 months the baby presented apneic spells and generalized hypertonicity. Brain ultrasound and EEG showed no anomalies, and the pediatric neurologist did not prescribe any therapy. At 8 months, after the occurrence of additional apneic episodes associated with cyanosis and generalized hypertonicity lasting 30-60 sec, the patient was referred to us for further investigations.

The growth was normal for the age, at physical examination, several dysmorphic features were noted: hirsute forehead with prominence of the metopic suture, apparent hypertelorism, epicanthic folds, short and upslanting palpebral fissures, short and bulbous nose, microstomia with a high palate, flat and long philtrum, micrognathia, and short neck. The hands were normal with a mild degree of interdigital webbing. Neurological examination showed normal motor development and mild global developmental delay.

External genitalia showed significant ambiguity. Labio-scrotal swellings were symmetrical; a perineal hypospadias with partial peno-scrotal inversion was present, even though the phallus was well developed, in length and girth (Fig. 1A). A palpable gonad was present in the right inguinal region. A pelvic ultrasound confirmed the presence of a gonad in the right inguinal canal, whereas no gonad was detected on the left side. Hormonal analysis (FSH, $\mathrm{LH}, 17-\mathrm{OH}$-progesterone, dehydroepiandrosterone sulphate and

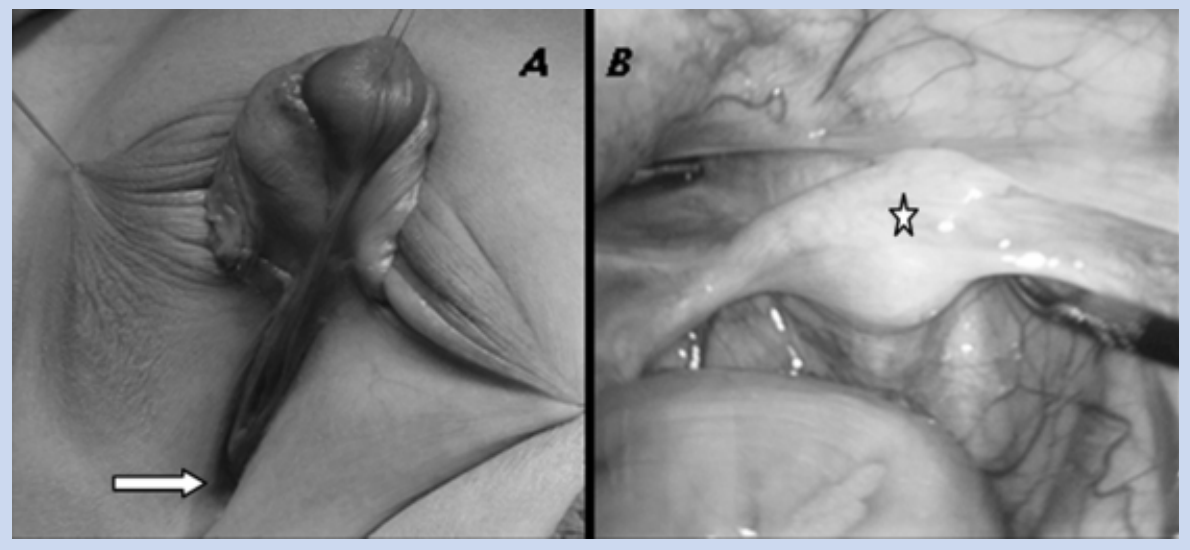

FIG. 1. Genital phenotype and laparoscopic view of the pelvis. A: Perineal hypospadias with partial peno-scrotal inversion. The arrow indicates the tiny vaginal opening, not clearly visible in the picture. B: The small uterus is indicated by an asterisk. 
anti-Müllerian hormone) showed normal values. A short hCG test $\left(5,000 \mathrm{UI} / \mathrm{m}^{2}\right.$ i.m. $)$ was also normal.

Cardiac ultrasound showed good functional correction of the congenital defect.

During hospitalization, the infant presented daily paroxysmal episodes of brief generalized tonic spasms with loss of consciousness and cyanosis, organized in clusters.

Although cerebral ultrasound, awake and sleep EEG and brain MRI were normal, antiepileptic therapy with phenobarbital was started, with prompt seizures control.

Array-CGH performed on genomic DNA using Agilent oligonucleotide array (Human Genome CGH microarray $4 \times 44 \mathrm{k}$; Agilent Technologies, Santa Clara, CA) following the manufacturer instructions, showed a small distal deletion of the short arm of chromosome 9 of $6.5 \mathrm{Mb}$ in size, described as: arr 9p24.3p24.1 $(204,367-6,582,172) x 1$ (probe alignments were referred to the human March 2006, hg 18, genomic assembly). This deletion, molecularly ascertained, can be defined cytogenetically as 46,XY, $\operatorname{del}(9)(\mathrm{p} 24.1)$, was confirmed by FISH analysis with a probe specific for $9 \mathrm{p}$ telomere on metaphase chromosomes (ToTelVysion ${ }^{\mathrm{TM}}$, Vysis, Abbott, IL), which showed a single fluorescent signal on 9p telomere.

Based on these findings, doctors and family decided on a male sex assignment and a correction of abnormal genitalia was planned.

At laparoscopy, a small uterus was found (Fig. 1B). On the left side there was a tiny linear gonad, connected to the uterus by a tubular structure resembling a fallopian tube devoid of fimbriae. On the right side, a round grayish gonad was found with a smooth surface, which was attached to a vas deferens. The uterus, the small vagina and the left gonad were resected en bloc.

The first stage of the urethroplasty was then undertaken by correcting the penile curvature and creating a neo-urethral plate with a graft from the foreskin. Standard orchidopexy and penoscrotal transposition completed the surgical procedure. On histologcal examination, the left mass was constituted by a neoplastic nodule of $11 \mathrm{~mm}$ in diameter, developing within a streak gonad. The biopsy of the other gonad showed testicular tissue. The neoplasia was composed by a collection of cellular nests surrounded by connective tissue stroma. The nests were solid, small, of oval or round shape, and contained a mixture of germ cells and sex cord derivates resembling immature Sertoli and granulosa cells, respectively.

The associated gonadal tissue was constituted by fibrous tissue. The histological picture was that of gonadoblastoma developing in a streak gonad, whose nature could not be determined.

\section{DISCUSSION}

A host of reported deletions of various sizes map CRs on the short arm of chromosome 9, related to two distinct clinical entities. A non-syndromic form of 46,XY sex reversal maps to band 9p24.3 at the extremity of chromosome 9p. The 9p-malformation syndrome maps more proximally, in an interval corresponding to band 9p22.3p24.1. Genital anomalies ranging from cryptorchidism and/or hypospadias to complete sex reversal can be found in $9 \mathrm{p}$ syndrome males, carriers of large terminal deletions encompassing both CRs [Christ et al., 1999].
The sex reversal $\mathrm{CR}$ has been assigned to a $1 \mathrm{Mb}$ interval, extending from the telomere to the DMRT genes [Flejter et al., 1998; Guioli et al., 1998; Raymond et al., 1999]. Although all three $D M R T$ genes in this region show sequence similarity among themselves and with Drosophila melanogaster and Caenorhabditis elegans sexual regulators doublesex and mab-3, respectively, $D M R T 1$ is the strongest candidate gene for sex reversal [Raymond et al., 1999; Ottolenghi and McElreavey, 2000]. In humans, DMRT1 is highly expressed in the genital ridge during male sexual differentiation and to the testes in adults. Functional studies in mice showed that Dmrt1 plays a key role in postnatal testicular differentiation and maintenance [Raymond et al., 2000; Krentz et al., 2009; Matson et al., 2011]. An apparent exception is represented by the case of two 46,XY siblings with sex reversal, carriers of a small $9 \mathrm{p}$ terminal deletion, spanning about $700 \mathrm{~kb}$ and excluding the DMRT gene cluster.

However, the proximal breakpoint was mapped in close proximity of the $5^{\prime}$ end of DMRT1, possibly causing a disruption of a regulatory sequence and perturbing its expression [Calvari et al., 2000].

Several attempts were made over the last years to precisely define a CR for the 9p-syndrome. Christ et al. [1999] assigned the CR to a $8 \mathrm{Mb}$ segment between D9S286 and D9S285 markers in 9p22p24, by comparing 24 patients with 9p terminal deletions and one [Wagstaff and Hemann, 1995] with an interstitial deletion, arising from a paternal balanced complex rearrangement between chromosomes 3, 8, and 9. This region was further restricted to a $4.7 \mathrm{Mb}$ interval, spanning from RP11-933C16 to D9S285 in 9p22.3p23, by Kawara et al. [2006] who described a 2-year-old boy with classical $9 \mathrm{p}$-syndrome phenotype, bearing a complex chromosome rearrangement with seven breakpoints involving chromosomes 2 and 9 . Subsequently, Faas et al. [2007] narrowed down the extent of this commonly deleted $9 \mathrm{p}$ region defining a smallest region of overlap (SRO) of 3.5 Mb, between RP11-33C16 and RP11-725C9 probes, in a patient with a dup/del 9p anomaly.

Finally, genotype-phenotype correlations in 13 deleted patients with and without trigonocephaly, led Swinkels et al. [2008] to further restrict the $9 \mathrm{p}$-syndrome CR to an interval of $300 \mathrm{~Kb}$, falling outside the SRO proposed by Faas et al. [2007] and flanked by RP11-271B19 and RP11-392B02 markers (Fig. 2).

Overall, the proposed regions do not explain a series of reported cases bearing small terminal deletions, whose clinical presentation is compatible with the 9p-malformation syndrome (see below), and complicate genotype-phenotype correlations. Furthermore, the lack of detailed molecular and/or phenotypic characterization of the majority of reported cases, as well as the possible contribution of other chromosomes involved in complex rearrangements, add complexity to the definition of a phenotypic map.

In an attempt to add some clarity to a rather confused issue, we compared our patient with clinical features of sevenreported 46,XY patients, carriers of isolated $9 \mathrm{p}$ terminal deletions, finely characterized by MLPA, microsatellite typing, FISH and array-CGH (Fig. 2 and Table I).

Of these seven patients, at least 3 (Cases 1-3 in Fig. 2 and Table I) have deletions that do not correspond to any of the CRs proposed so far, in spite of having some clinical features resembling the $9 \mathrm{p}$ phenotype. One patient had a $1.2 \mathrm{Mb}$ deletion associated with 


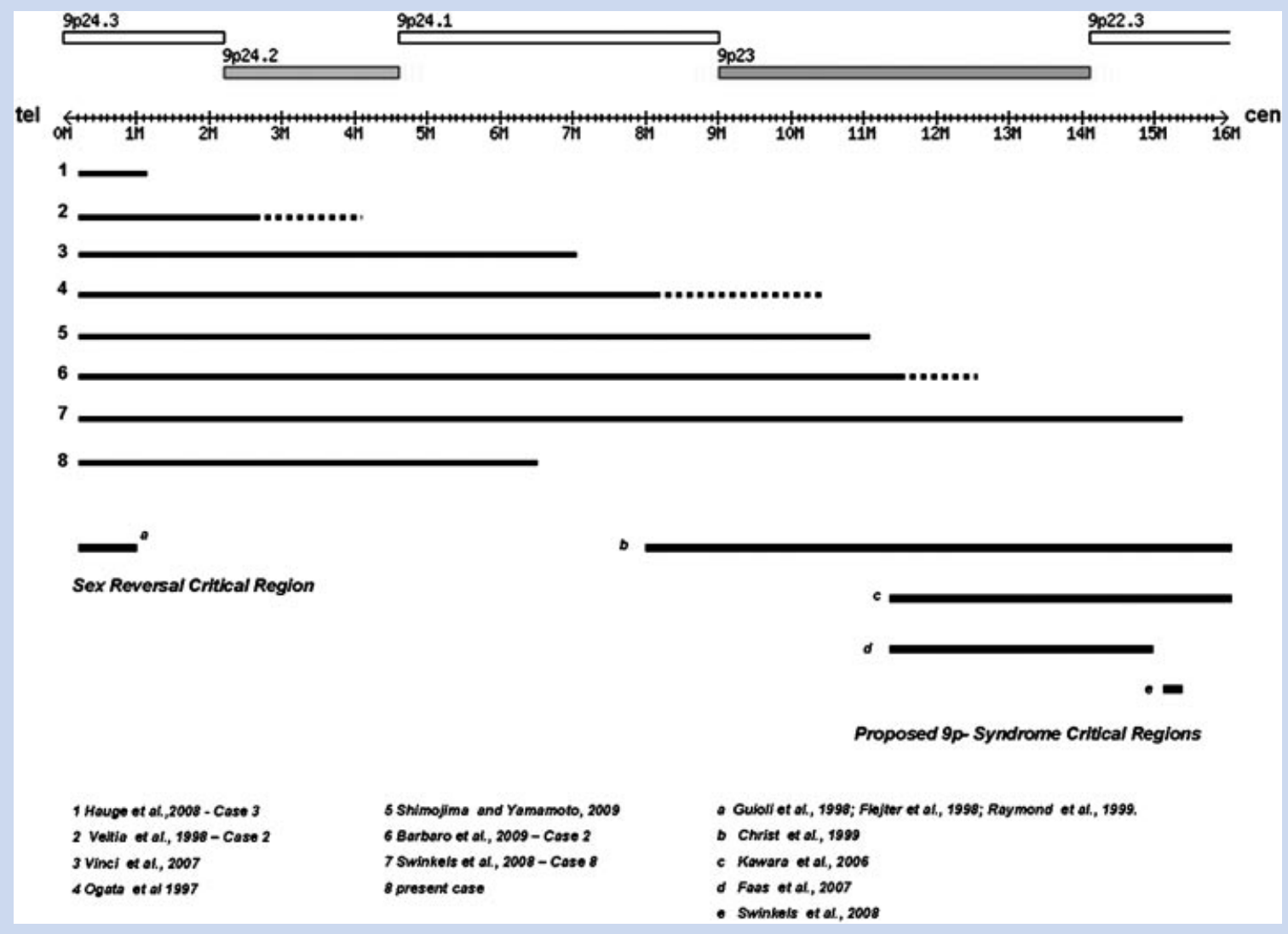

FIG. 2. Schematic representation of the distal $16 \mathrm{Mb}$ of the short arm of chromosome 9 from the telomere to 9 p22.3 band. Bars from 1 to 8 indicate molecular defined terminal deletions in seven previously reported patients (1-7) and in present case (8); dotted lines indicate a uncertain proximal breakpoint definition. Bars (a) and (b-d) illustrate the critical region for sex reversal and for 9p-consensus phenotype, respectively.

intellectual disability, distinctive facial appearance, and mild prominence of the metopic suture [Hauge et al., 2008]. Another patient with a $7 \mathrm{Mb}$ terminal deletion presented with intellectual disability, behavior problems, and gonadal dysgenesis [Vinci et al., 2007]. A phenotype with gonadal dysgenesis, learning difficulties and affective disorder was also described in a subject with a small terminal deletion of about $3 \mathrm{Mb}$ [Veitia et al., 1998].

Our patient presented with complex abnormalities of genitalia, including a congenital gonadoblastoma, associated with facial features typical of the 9p-syndrome. He did not have frank trigonocephaly, but rather a prominent forehead, as described in many other cases of this syndrome [Ogata et al., 2001; Barbaro et al., 2009].

There are only a small number of patients with $9 \mathrm{p}$-syndrome in whom gonads have been examined in detail. A gonadoblastoma was reported in only four patients with 9p-syndrome and sex reversal [Huret et al., 1988; Mc Donald et al., 1997; Muroya et al., 2000; Livadas et al., 2003], leading to hypothesize the existence of a gonadoblastoma suppressor gene in the distal portion of chromosome 9p.

The present report is the first description of a $9 p$ deletion in a patient with a complex phenotype, including neurological findings, features of the 9p-malformation syndrome, sex reversal, and gonadal dysgenesis with gonadoblastoma.
The neurological findings consisted of mild developmental delay and epileptic seizures. Almost all previously described cases presented developmental delay of variable severity, particularly behavior problems, language impairment, or learning difficulties. These aspects are difficult to measure precisely in our patient, considering his very young age.

Epilepsy consisted of generalized tonic seizures in clusters. Unfortunately, we could not perform an ictal EEG, so that a focal onset cannot be excluded. Even though we did not find paroxysmal discharges in wakefulness and sleep interictal EEG, seizure semeiology and prompt response to phenobarbital confirmed their epileptic nature. It should be noted that seizure disorder with normal interictal EEG is not uncommon, occurring for instance in benign familial and non-familial infantile seizures [Caraballo et al., 2003].

Epileptic seizures are rarely reported in patients with 9p deletion syndrome. In Case 1 of Hauge et al. [2008] there was a clinical history of suspected seizures, not supported by EEG studies, while Case 8 presented febrile seizure at 2 years followed by a variant of Landau-Kleffner syndrome. The authors suggested that the DOCK8 gene deletion may play a role in seizures. DOCK8 is located $\sim 400 \mathrm{~kb}$ distal to the $D M R T 1$ gene. It is involved in the reorganization of the actin filament system and is expressed in many organs, including heart and brain, although at low levels [Vinci et al., 2007]. 


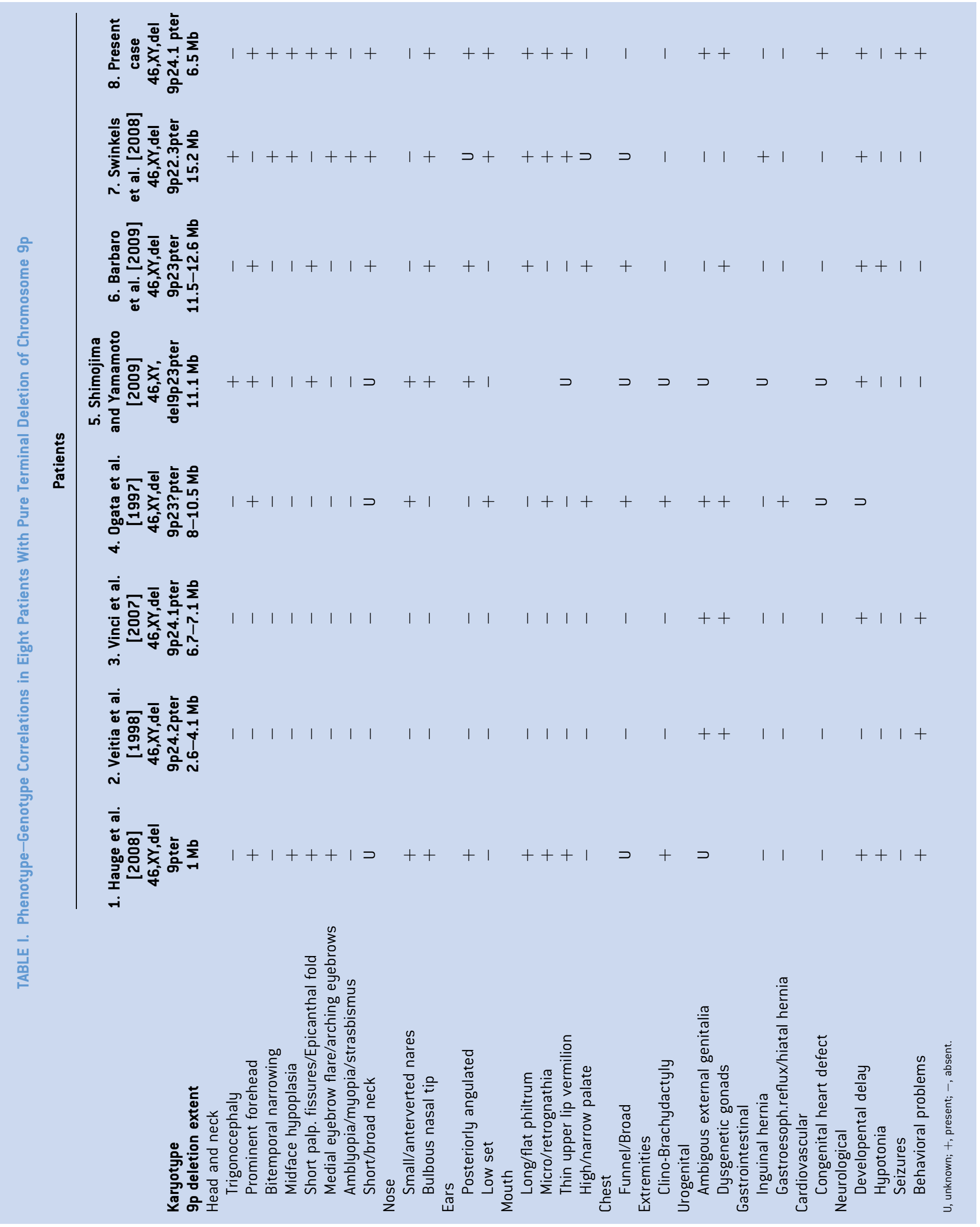


Our patient has a congenital heart defect that one could tentatively relate to malfunction of $D O C K 8$.

Based on evidence gathered from the study of this patient, we propose that the region associated with the $9 \mathrm{p}$-core phenotype lies between chromosome bands 9p22 and 9p24 as previously suggested [Christ et al., 1999; Kawara et al., 2006; Faas et al., 2007; Swinkels et al., 2008], and that atypical cases, where smaller terminal deletions are associated with $9 \mathrm{p}$-syndrome clinical features, may result from the perturbation of proximally located gene(s), exerted by the deletion of distal regulatory element(s).

\section{REFERENCES}

Alfi O, Donnell GN, Crandall BF, Derencsenyi A, Menon R. 1973. Deletion of the short arm of chromosome no.9 (46,9p-): A new deletion syndrome. Ann Genet 16:17-22.

Barbaro M, Balsamo A, Anderlid BM, Myhre AG, Gennari M, Nicoletti A, Pittalis MC, Oscarson M, Wedell A. 2009. Characterization of deletions at $9 \mathrm{p}$ affecting the candidate regions for sex reversal and deletion $9 \mathrm{p}$ syndrome by MLPA. Eur J Hum Genet 17:1439-1447.

Calvari V, Bertini V, De Grandi A, Peverali G, Zuffardi O, Ferguson-Smith M, Knudtzon J, Camerino G, Borsani G, Guioli S. 2000. A new submicroscopic deletion that refines the $9 \mathrm{p}$ region for sex reversal. Genomics 65:203-212.

Caraballo RH, Cersósimo RO, Espeche A, Fejerman N. 2003. Benign familial and non-familial infantile seizures. Epileptic Disord 5:45-49.

Christ LA, Crowe CA, Micale MA, Conroy JM, Schwartz S. 1999. Chromosome breakage hotspots and delineation of the critical region for the 9p-deletion syndrome. Am J Hum Genet 65:1387-1395.

Faas BH, de Leeuw N, Mieloo H, Bruinenberg J, de Vries BB. 2007. Further refinement of the candidate region for monosomy $9 \mathrm{p}$ syndrome. Am J Med Genet Part A 143A:2353-2356.

Flejter WL, Fergestad J, Gorski J, Varvill T, Chandrasekharappa S. 1998. A gene involved in XY sex reversal is located on chromosome 9, distal to marker D9S1779. Am J Hum Genet 63:794-802.

Fujimoto Y, Okuyama T, Iijima M, Tanaka T, Horikawa R, Yamada K, Ogata T. 2004. Genitourinary phenotype in XX patients with distal 9p monosomy. Mol Genet Metab 82:173-179.

Guioli S, Schmitt K, Critcher R, Bouzyk M, Spurr NK, Ogata T, Hoo JJ, Pinsky L, Gimelli G, Pasztor L, Goodfellow PN. 1998. Molecular analysis of $9 p$ deletions associated with XY sex reversal: Refining the localization of a sex-determining gene to the tip of the chromosome. Am J Hum Genet 63:905-908.

Hauge X, Raca G, Cooper S, May K, Spiro R, Adam M, Martin CL. 2008. Detailed characterization of, and clinical correlations in, 10 patients with distal deletions of chromosome 9p. Genet Med 10:599-611.

Hou JW. 2003. Del (9p) syndrome: Report of four cases. Acta Paediatr Taiwan 44:50-53.

Huret JL, Leonard C, Forestier B, Rethoré MO, Lejeune J. 1988. Eleven new cases of del (9p) features from 80 cases. Med J Genet 25:741-749.

Kawara H, Yamamoto T, Harada N, Yoshiura K, Niikawa N, Nishimura A, Mizuguchi T, Matsumoto N. 2006. Narrowing candidate region for monosomy 9p syndrome to a 4.7-Mb segment at 9p22.2-p23. Am J Med Genet Part A 140A:373-377.

Krentz AD, Murphy MW, Kim S, Cook MS, Capel B, Zhu R, Matin A, Sarver AL, Parker KL, Griswold MD, Looijenga LH, Bardwell VJ, Zarkower D. 2009. The DM domain protein DMRT1 is a dose-sensitive regulator of fetal germ cell proliferation and pluripotency. Proc Natl Acad Sci USA 106:22323-22328.

Livadas S, Mavrou A, Sofocleous C, van Vliet-Constantinidou C, Dracopoulou M, Dacou-Voutetakis C. 2003. Gonadoblastoma in a patient wih $\operatorname{del}(9)(\mathrm{p} 22)$ and sex reversal: Report of a case and review of the literature. Cancer Genet Cytogenet 143:174-177.

Matson CK, Murphy MW, Sarver AL, Griswold MD, Bardwell VJ, Zarkower D. 2011. DMRT1 prevents female reprogramming in the postnatal mammalian testis. Nature 476:101-104.

Mc Donald TM, Flejter W, Sheldon S, Putzi JP, Gorski LJ. 1997. XY sex reversal monosomy and gonadal dysgenesis due to 9p24 monosomy. Am J Med Genet 73:321-326.

Muroya K, Okuyama T, Goishi K, Ogiso Y, Fukuda S, Kameyama J, Sato H, Suzuki Y, Terasaki H, Gomyo H, Wakui K, Fukushima Y, Ogata T. 2000. Sex-determining gene(s) on distal 9p: Clinical and molecular studies in six cases. J Clin Endocrinol Metab 85:3094-3100.

Ogata T, Muroya K, Matsuo N, Hata J, Fukushima Y, Suzuki Y. 1997. Impaired male sex development in an infant with molecularly defined partial 9p monosomy: Implication for a testis forming gene(s) on 9p. J Med Genet 34:331-334

Ogata T, Muroya K, Ohashi H, Mochizuki H, Hasegawa T, Kaji M. 2001. Female gonadal development in XX patients with distal 9p monosomy. Eur J Endocrinol 145:613-617.

Ottolenghi C, McElreavey K. 2000. Deletions of $9 p$ and the quest for a conserved mechanism of sex determination. Mol Genet Metab 71: 397-404.

Raymond CS, Parker ED, Kettlewell JR, Brown LG, Page DC, Kusz K, Jaruzelska J, Reinberg Y, Flejter WL, Bardwell VJ, Hirsch B, Zarkower D. 1999. A region of human chromosome $9 p$ required for testis development contains two genes related to known sexual regulators. Hum Mol Genet 8:989-996.

Raymond CS, Murphy MW, O'Sullivan MG, Bardwell VJ, Zarkower D. 2000. Dmrt1, a gene related to worm and fly sexual regulators, is required for mammalian testis differentiation. Genes Dev 14:2587-2595.

Shashi V, Berry D, Stamper TH, Pettenati M. 1998. A further case of choanal atresia in the deletion (9p) syndrome. Am Med J Genet 80:440.

Shimojima K, Yamamoto T. 2009. Investigation of the candidate region for trigonocephaly in a patient with monosomy 9p syndrome using arrayCGH. Am J Med Genet Part A 149A:1076-1080.

Swinkels ME, Simons A, Smeets DF, Vissers LE, Veltman JA, Pfundt R, de Vries BB, Faas BH, Schrander-Stumpel CT, McCann E, Sweeney E, May P, Draaisma JM, Knoers NV, van Kessel AG, van Ravenswaaij-Arts CM. 2008. Clinical and cytogenetic characterization of 13 Dutch patients with deletion 9p syndrome: Delineation of the critical region for a consensus phenotype. Am J Med Genet Part A 146A:1430-1438.

Veitia RA, Nunes M, Quintana-Murci L, Rappaport R, Thibaud E, Jaubert F, Fellous M, McElreavey K, Gonçalves J, Silva M, Rodrigues JC, Caspurro M, Boieiro F, Marques R, Lavinha J. 1998. Swyer syndrome and 46,XY partial gonadal dysgenesis associated with 9p deletions in the absence of monosomy-9p syndrome. Am J Hum Genet 63:901-905.

Vinci G, Chantot-Bastaraud S, El Houate B, Lortat-Jacob S, Brauner R, McElreavey K. 2007. Association of deletion 9p,46,XY gonadal dysgenesis and autistic spectrum disorder. Mol Hum Reprod 13:685-689.

Wagstaff J, Hemann M. 1995. A familial "balanced" 3;9 translocation with cryptic $8 \mathrm{q}$ insertion leading to deletion and duplication of $9 \mathrm{p} 23$ loci in siblings. Am J Hum Genet 56:302-309.

Young RS, Reed T, Hodes ME, Palmer CG. 1982. The dermatoglyphic and clinical features of the $9 \mathrm{p}$ trisomy and partial $9 \mathrm{p}$ monosomy syndromes. Hum Genet 62:31-39. 